\author{
Stepan Melnyk and Bohdan Dzinyak
}

\title{
SELECTIVITY OF FORMATION AND YIELD OF DICARBOXYLIC ACID MON O- AND DIESTERS UNDER STATIONARY CONDITIONS
}

\author{
Lviv Polytechnic National Univeristy \\ 12, S. Bandery str., 79013 Lviv, Ukraine; st_melnyk@yahoo.com
}

Received: December 02, 2014 / Revised: M arch 02, 2015 / Accepted: M ay 02, 2015

(C) Melnyk S., Dzinyak B., 2015

\begin{abstract}
The effect of temperature, catalyst type, alcohol and dicarboxylic acid structures, as well as reagents ratio on the selectivity of formation and yield of mono- and diesters has been determined under stationary conditions for adipic (AA) and succinic acids (SA) esterification by $\mathrm{C}_{2}-\mathrm{C}_{5}$ aliphatic alcohols. It has been proved by the theory and experiments that maximum selectivity of dicarboxylic acids (DCA) monoesters formation during their esterification by alcohols is achieved at the ratio between flow rate constants of monoester and DCA less than 0.1. The high yield of monoester (40-60\%) was found to be for only such reaction systems as SA-2-methylpropan-1ol (catalysts $\mathrm{H}_{2} \mathrm{SO}_{4}$ and $p$-toluenesulfoacid) and SApentan-1-ol (catalyst $p$-toluenesulfoacid).
\end{abstract}

Keywords: selectivity, yield, monoether, dicarboxylic acid, $\mathrm{C}_{2}-\mathrm{C}_{5}$ alcohols.

\section{Introduction}

The aim of dicarboxylic acids (DCA) esterification by alcohols is providing maximum yield of diesters (DE) used as high-boiling solvents, plasticizers, lubricants, etc. At the same time the intermediate products of DCA and alcohol interaction - monoesters (ME) - are used as a raw material for the organic synthesis, reagents for electrochemical synthesis of high diesters, an additive to gasoline $(0.1-0.3 \%)$ that improves combustion process and decreases $\mathrm{CO}$ and $\mathrm{NO}_{\mathrm{x}}$ content in exhausts, etc. $[1,2]$. Monoesters of succinic and glutaric acids are obtained via interaction of their anhydrides with methanol or ethanol without catalysts. Another method of DCA monoesters obtaining is a partial saponification of corresponding DE by alkaline solutions in absolute alcohol at room temperature. In particular, the yield of malonic acid monoesters is 75$82 \%$ ( $\mathrm{KOH}$ hydrolysis), the yield of nonandicarboxylic acid monoesters is $60-64 \%\left(\mathrm{Ba}(\mathrm{OH})_{2}\right.$ hydrolysis) [3].
DCA monoesters are also obtained via the reaction between diester, alcohol and corresponding acid [2].

The aim of this work is to determine the effect of temperature, catalyst type, alcohol and dicarboxylic structures, as well as reagents ratio on the selectivity of formation and yield of mono- and diesters under stationary conditions for the reaction between DCA and $\mathrm{C}_{2}-\mathrm{C}_{5}$ alcohols and to evaluate the prospects of monoesters obtaining via this method.

\section{Experimental}

The regularities of adipic (AA) and succinic (SA) acids esterification by $\mathrm{C}_{2}-\mathrm{C}_{5}$ aliphatic alcohols were studied in a glass temperature-controlled reactor within 333-368 K under stationary conditions. One more condition was that the reaction temperature was lower than the boiling temperature of water and alcohol azeotropic mixture. The reactor was equipped with a back condenser and a mixer with water seal. The rotation speed was $500 \mathrm{rev} / \mathrm{min}$. After definite time intervals the samples were withdrawn to determine the acid number of DCA esterification products and to analyze the formed DE by chromatography.

The beginning of the reaction was the moment of catalyst introduction into the mixture heated to the reaction temperature. The alcohol:DCA molar ratio was (16-24):1. Sulfate acid, $p$-toluenesulfoacid (TSA) and stanum(II) perfluorine(4-methyl-3,6-dioxaoctane)sulfonate $\left(\operatorname{Sn}(\operatorname{pfos})_{2}\right)$ were used as catalysts.

Under great excess of an alcohol the esterification reaction proceeds according to the scheme:

$$
D C A \stackrel{k_{1, f}}{\longrightarrow} M E \stackrel{k_{2, e f}}{\longrightarrow} D E
$$

where $k_{1, e f}$ - effective rate constant of DCA conversion into $\mathrm{ME}, \mathrm{s}^{-1} ; k_{2, e f}$ - effective reaction constant of $\mathrm{ME}$ conversion into DE, $\mathrm{s}^{-1}$. 
The reaction reversibility may be neglected.

Acid number of the reaction mixture $A N$ is determined according to the procedure described in [4]. The relative error was $\pm 3 \%$.

Acid number is recalculated from $\mathrm{mg} \mathrm{KOH} / \mathrm{g}$ for $\mathrm{mol} / \mathrm{dm}^{3}\left(C_{A N}\right)$ according to the formula (1):

$$
C_{A N}=\frac{A N \cdot 10^{-3} \cdot \rho}{56 \cdot 10^{-3}}=\frac{A N \cdot \rho}{56}
$$

where $A N$ - acid number, $\mathrm{mg} \mathrm{KOH} / \mathrm{g} ; \rho$ - mixture density, $\mathrm{g} / \mathrm{cm}^{3} ; 56-\mathrm{KOH}$ molar mass, $\mathrm{g} / \mathrm{mol}$.

DE content in the esterification products is determined using a gas-liquid chromatograph "Tsvet-100" with a thermal conductivity detector. To separate the components the column of $1 \mathrm{~m}$ length and $3 \mathrm{~mm}$ diameter is filled by a stationary phase of $5 \%$ Silicone SE30 over Chromaton N-AW. Helium with a flow rate of $3 \mathrm{dm}^{3} / \mathrm{h}$ is a gas-carrier; current strength at the detector is $120 \mathrm{~mA}$; sample volume is $2 \mu \mathrm{l}$. Evaporator temperature is $523 \mathrm{~K}$, detector temperature is $503 \mathrm{~K}$. The temperature of the column was varied within $373-448 \mathrm{~K}$ depending on DE type. The samples (if necessary) were dissolved in propan-2-ol relative to the weight.

To determine the current concentrations of DCA and $\mathrm{ME}\left(\mathrm{mol} / \mathrm{dm}^{3}\right)$ the combined equation (2) is used:

$$
\left\{\begin{array}{l}
C_{D C A, 0}=C_{D C A}+C_{M E}+C_{D E} \\
C_{A N}=2 C_{D C A}+C_{M E}
\end{array}\right.
$$

where $C_{D C A, O}$ and $C_{D C A}-$ DCA initial and current concentrations, respectively, mol/ $\mathrm{dm}^{3} ; C_{M E}-\mathrm{ME}$ current concentration, $\mathrm{mol} / \mathrm{dm}^{3} ; C_{D E}-\mathrm{DE}$ current concentration, $\mathrm{mol} / \mathrm{dm}^{3} ; C_{A N}$ - carboxy groups acid number to recalculate for $\mathrm{mol} / \mathrm{dm}^{3}$.

Hence, ME current concentration is calculated according to Eq. (3):

$$
C_{M E}=2\left(C_{D C A, 0}-C_{D E}\right)-C_{A N}
$$

and DCA concentration:

$$
C_{D C A}=C_{A N}-C_{D C A, 0}+C_{D E}
$$

For the irreversible reaction of the first order the time of achieving ME maximum concentration is:

$$
\tau_{\max }=\frac{1}{k_{2, e f}-k_{1, e f}} \ln \frac{k_{2, e f}}{k_{1, e f}}
$$

and maximum yield of monoester is:

$$
\eta_{M E, \text { max }}=\left(\frac{k_{2, e f}}{k_{1, e f}}\right)^{\frac{k_{2, e f}}{k_{1, e f}-k_{2, e f}}}
$$

\section{Results and Discussion}

The change in the yield of intermediate product monobutyladipinate (MBA) is observed (Fig. 1) during
AA esterification by butan-1-ol within the temperature range of 343-363 K with the increase in AA conversion $X$. Such change is typical for the consecutive reaction: at first MBA yield achieves maximum (42-45\%) and then decreases; the yield of the final product - dibutyladipinate (DBA) neatly increases. The same behavior is observed (Fig. 2) for SA esterification by 3-methylbutan-1-ol in the presence of stanum(II) perfluorine(4-methyl-3,6dioxaoctane)sulfonate aprotic catalyst. However, during the catalysis in the presence of $\mathrm{Sn}$ (pfos) $)_{2}$ the yield of monoester - monoisoamylsuccinate (MiAS) is considerably higher $(\sim 7 \%)$ compared with that in the presence of Bronsted-Lowry acid. SA conversion is almost $96 \%$. The change in temperature within a narrow range $(20 \mathrm{~K})$ affects the products yield only at high values of DCA conversion, namely at higher temperature the ME yield is higher (Figs. 1 and 2).

The small difference (3-7\%) between ME and DE yields is observed under the same conditions of AA esterification by butan-1-ol and penta-1-ol, as well as AA and SA esterification by butan-1-ol in the presence of TSA. This difference increases with the increase in DCA conversion (Fig. 3).

Obviously, the catalyst has a greater influence on the products composition than reagents structure (Figs. 1, 2 and 4$)$.

The ratio between rate constants $k_{2} / k_{1}$ is the parameter providing the maximum concentration, time for its achieving and selectivity of the intermediate product formation. To estimate the effect of the mentioned value on the products composition we calculated the corresponding rate constants $k_{1}$ and $k_{2}$ using previously determined preexponential factor and activation energy of AA and SA esterification by $\mathrm{C}_{2}-\mathrm{C}_{5}$ alcohols $[5,6]$. For the assumed classical scheme of the consecutive reaction it is typically that the higher ratio $k_{1} / k_{2}$, the closer $\mathrm{ME}$ maximum concentration to the reaction beginning and the lower its value [7].

One can see from Table 1 that time for achieving ME maximum yield and ME yield calculated according to Eqs. (5) and (6) differs from their experimental values. As a rule, the mentioned values are achieved at high values of DCA conversion $(\sim 0.6 \pm 0.1)$, therefore the reaction reversibility influences the difference between them. Actually, during DCA esterification by large excess of alcohol under stationary conditions the ME maximum yield is achieved later and its value is higher than the calculated one. The reason is water inhibition of diester formation from monoester at the deep stages of reagents conversion. According to Ref. [5, 6] we calculated the rate constants for the temperature of esterification technolo- 


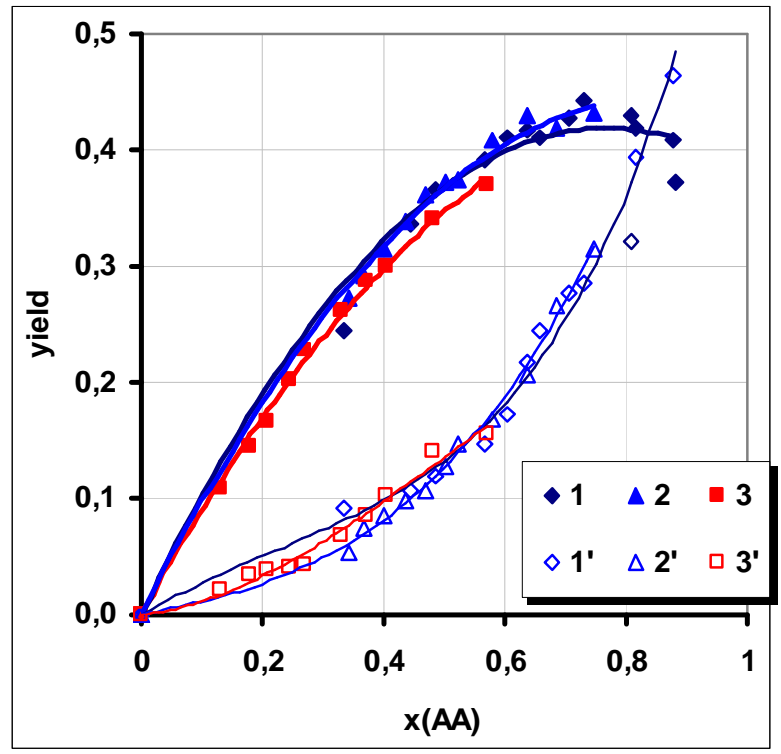

Fig. 1. Dependence of MBA (1, 2, 3) and DBA (1', 2' and 3') yields on AA conversion at different temperatures $(\mathrm{K})$ :

363 (1); 353 (2) and 343 (3).

$C(\mathrm{TSA})=1.4 \cdot 10^{-2} \mathrm{~mol} / \mathrm{dm}^{3}$, butan-1-ol (BA):AA = 20:1 (mol)

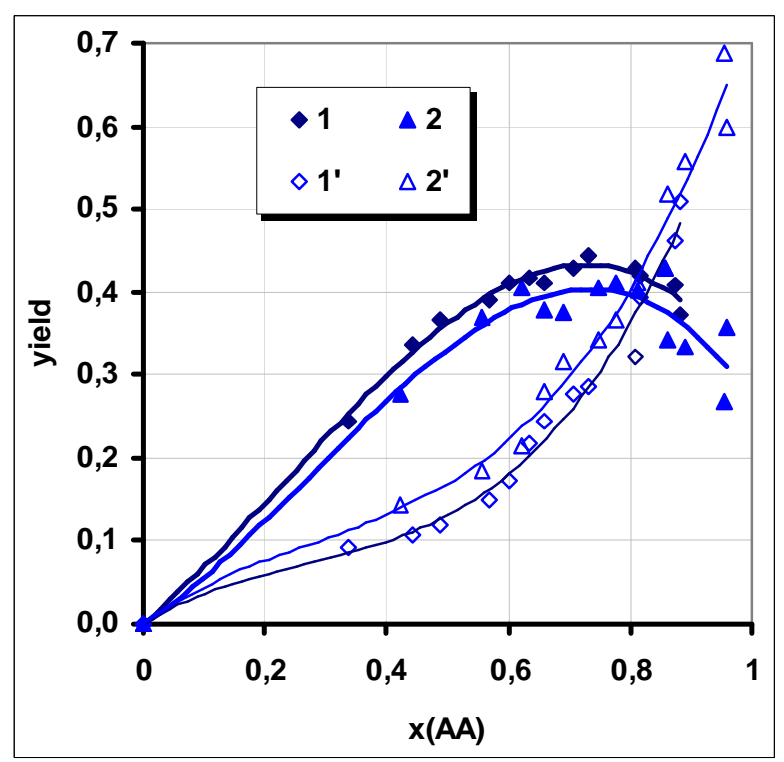

a)

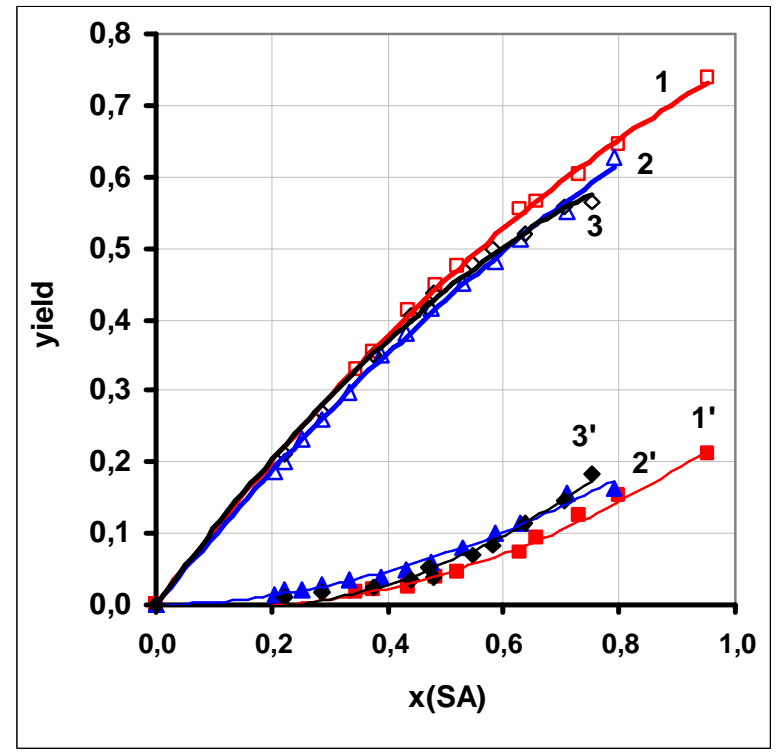

Fig. 2. Dependence of MiAS $(1,2,3)$ and diisoamyl succinate (DiAS) (1', 2', 3') yields on SA conversion at different temperatures (K): 1 - 364 (1); 354 (2) and 350 (3). $C\left(\operatorname{Sn}(\text { pfos })_{2}\right)=1.5 \cdot 10^{-2} \mathrm{~mol} / \mathrm{dm}^{3}, 3-$ methylbutan-1-ol (iAA):SA = 16:1 (mol)

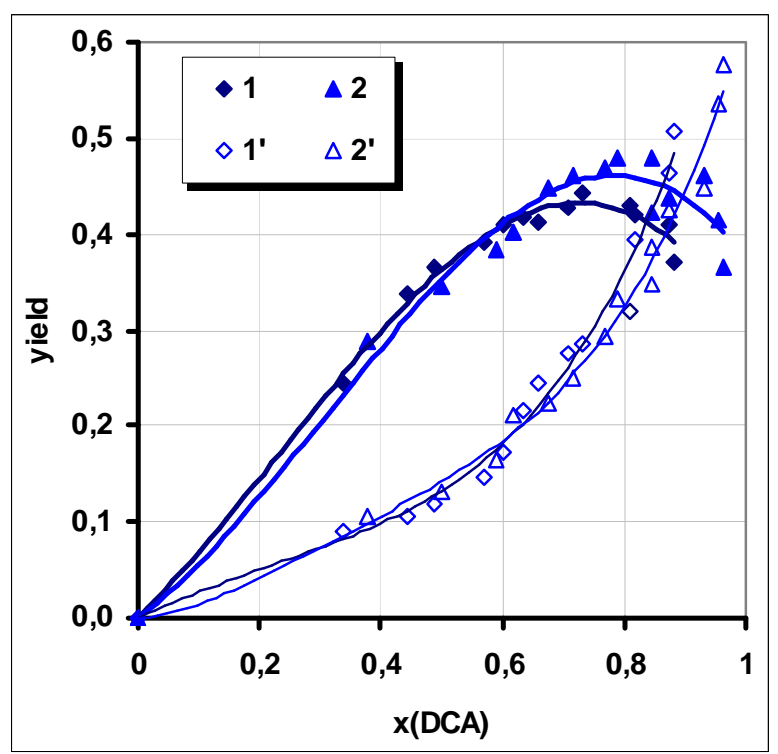

b)

Fig. 3. Effect of alcohol (a) and DCA (b) composition on the dependence:

a) yield of MBA (1), MAA (2), DBA (1') and DAA (2') on AA conversion in the reaction with butan-1-ol and pentan-1-ol. $T=363 \mathrm{~K}, C(\mathrm{TSA})=1.4 \cdot 10^{-2} \mathrm{~mol} / \mathrm{dm}^{3}$, alcohol:AA $=20: 1(\mathrm{~mol})$;

b) yield of MBA (1), monobutylsuccinate (2), DBA (1') and dibutylsuccinate (2') on AA and SA conversions in the reaction with butan-1-ol. $T=363 \mathrm{~K}, C(\mathrm{TSA})=1.4 \cdot 10^{-2} \mathrm{~mol} / \mathrm{dm}^{3}, \mathrm{BA}: \mathrm{DCA}=20: 1(\mathrm{~mol})$ 


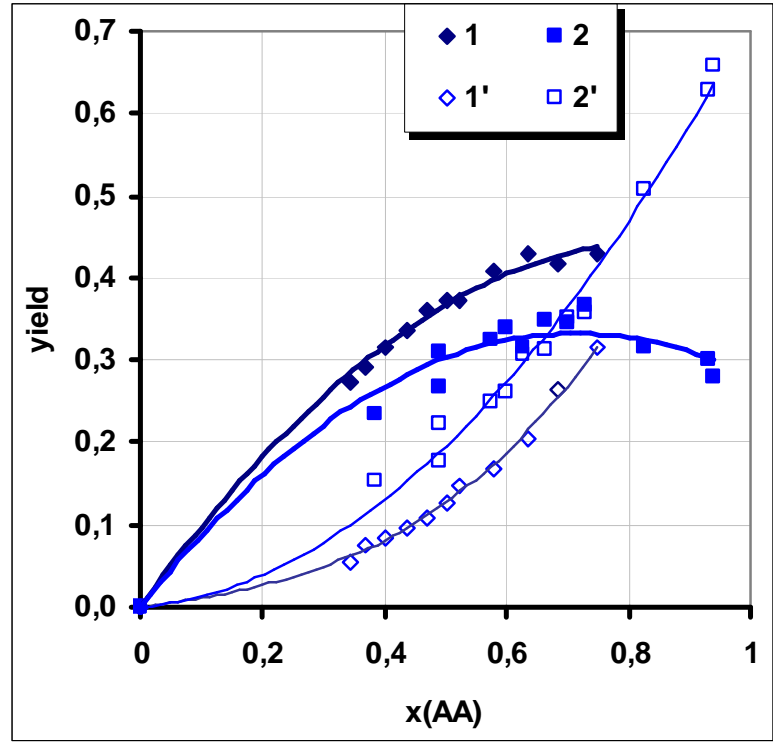

Fig. 4. Dependence of MBA $(1,2)$ and DBA $(1,2$ ') yields on AA conversion for the esterification in the presence of TSA (1) and $\mathrm{H}_{2} \mathrm{SO}_{4}$ (2). $T=353 \mathrm{~K}$; $C($ cat $)=1.45 \cdot 10^{-2} \mathrm{~mol} / \mathrm{dm}^{3}$, $\mathrm{BA}: \mathrm{AA}=20: 1(\mathrm{~mol})$

Table 1

Calculated and experimental values of achieving time and ME maximum yield

\begin{tabular}{|c|c|c|c|c|c|c|c|c|}
\hline \multirow{4}{*}{$T, \mathrm{~K}$} & \multicolumn{2}{|c|}{ Calculated } & \multicolumn{2}{|c|}{ Experimental } & \multicolumn{2}{|c|}{ Calculated } & \multicolumn{2}{|c|}{ Experimental } \\
\hline & time, $\min$ & yield & time, $\min$ & yield & time, $\min$ & yield & time, $\min$ & yield \\
\hline & \multicolumn{4}{|c|}{ catalyst $-\mathrm{TSA}$} & \multicolumn{4}{|c|}{ catalyst $-\mathrm{H}_{2} \mathrm{SO}_{4}$} \\
\hline & \multicolumn{8}{|c|}{ AA - ethanol } \\
\hline 338 & 43 & 0.354 & 60 & 0.420 & 37 & 0.332 & 60 & 0.422 \\
\hline 343 & 34 & 0.357 & 40 & 0.425 & 28 & 0.308 & 60 & 0.355 \\
\hline \multirow[t]{2}{*}{348} & 29 & 0.352 & 30 & 0.376 & 20 & 0.318 & 35 & 0.333 \\
\hline & \multicolumn{8}{|c|}{ SA - ethanol } \\
\hline 338 & 60 & 0.342 & 50 & 0.284 & 43 & 0.211 & 60 & 0.236 \\
\hline 343 & 45 & 0.344 & 40 & 0.390 & 29 & 0.209 & 60 & 0.323 \\
\hline \multirow[t]{2}{*}{348} & 33 & 0.332 & 30 & 0.336 & 22 & 0.230 & 23 & 0.246 \\
\hline & \multicolumn{8}{|c|}{ AA - propan-1-ol } \\
\hline 343 & 20 & 0.152 & 25 & 0.205 & 12 & 0.085 & 13 & 0.096 \\
\hline 353 & 14 & 0.197 & 15 & 0.248 & 9 & 0.101 & 15 & 0.154 \\
\hline \multirow[t]{2}{*}{363} & 8 & 0.104 & 13 & 0.050 & 7 & 0.127 & 35 & 0.207 \\
\hline & \multicolumn{8}{|c|}{ AA - 2-methyl-propan-1-ol } \\
\hline 343 & 22 & 0.344 & 30 & 0.425 & 40 & 0.277 & 70 & 0.331 \\
\hline 353 & 14 & 0.390 & 20 & 0.427 & 28 & 0.282 & 60 & 0.389 \\
\hline \multirow[t]{2}{*}{363} & 9 & 0.396 & 15 & 0.438 & 18 & 0.296 & 40 & 0.289 \\
\hline & \multicolumn{8}{|c|}{ AA - butan-1-ol } \\
\hline 343 & 73 & 0.352 & 60 & 0.369 & 27 & 0.255 & 50 & 0.382 \\
\hline 353 & 43 & 0.382 & 40 & 0.430 & 18 & 0.307 & 30 & 0.368 \\
\hline \multirow[t]{2}{*}{363} & 26 & 0.402 & 30 & 0.443 & 12 & 0.321 & 25 & 0.379 \\
\hline & \multicolumn{8}{|c|}{ AA - 3-methylbutan-1-ol } \\
\hline 343 & 47 & 0.285 & 43 & 0.339 & 33 & 0.110 & 30 & 0.150 \\
\hline 353 & 29 & 0.94 & 28 & 0.361 & 21 & 0.134 & 25 & 0.158 \\
\hline \multirow[t]{2}{*}{363} & 21 & 0.301 & 20 & 0.390 & 14 & 0.161 & 23 & 0.173 \\
\hline & \multicolumn{8}{|c|}{ SA - pentan-1-ol } \\
\hline 343 & 37 & 0.312 & 41 & 0.388 & 42 & 0.134 & 70 & 0.193 \\
\hline 353 & 25 & 0.354 & 35 & 0.420 & 27 & 0.164 & 50 & 0.217 \\
\hline 363 & 18 & 0.387 & 23 & 0.405 & 19 & 0.211 & 23 & 0.210 \\
\hline
\end{tabular}




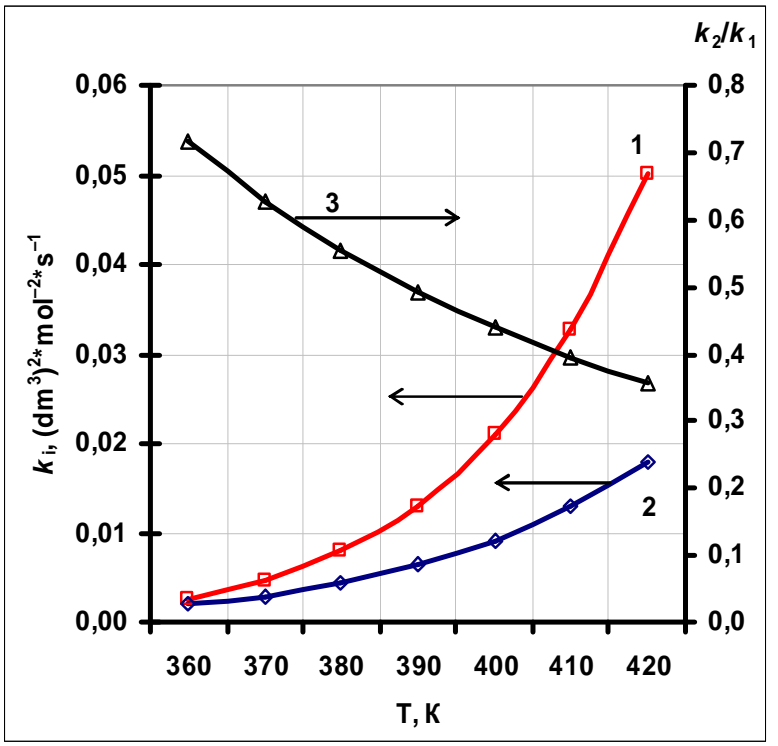

a)

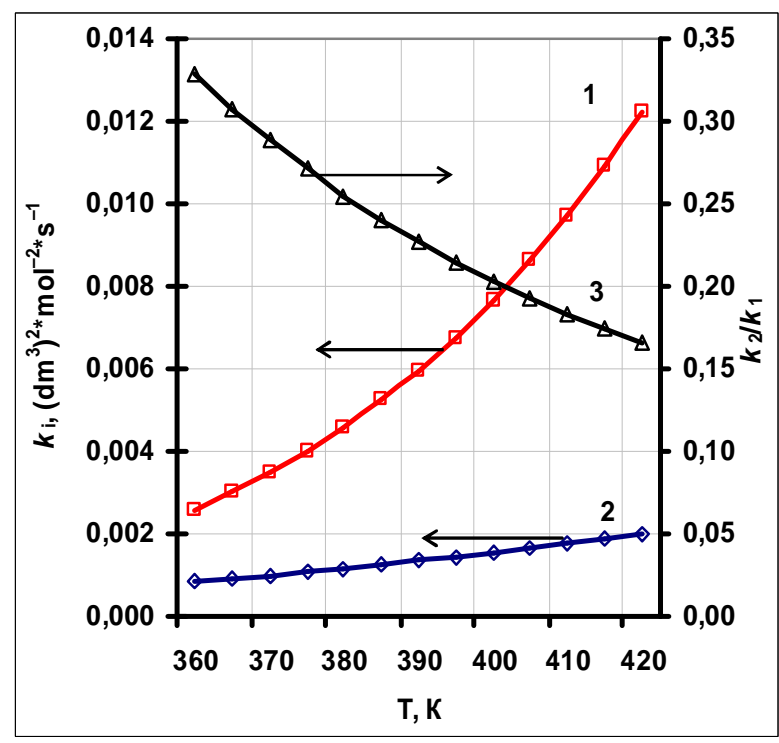

b)

Fig. 5. Dependence of the calculated rate constants of AA esterification by butan-1-ol in the presence of TSA (a) and SA esterification by 3-methylbutan-1-ol in the presence of $\mathrm{Sn}(\mathrm{pfos})_{2}(\mathrm{~b})$ and their ratio on the temperature: DCA flow rate constant $k_{1}(1)$; rate constant of monoester conversion $\mathrm{k}_{2}(2)$ and ratio between esterification rate constants $k_{2} / k_{1}(3)$

gical process carried out under mixture boiling and water distillation. For example, AA esterification by butan-1-ol is carried out under mixture boiling within the temperature range from the boiling point of azeotropic mixture butan1-ol-water $(-365 \mathrm{~K})$ to the boiling point of alcohol $(\sim 390 \mathrm{~K})$ and higher temperatures (under the conditions of alcohol excess).

Fig. 5a represents the dependence of the calculated rate constants and the $k_{2} / k_{1}$ ratio on the temperature for AA esterification by butan-1-ol in the presence of TSA within 360-420 K temperature range. The increase in temperature decreases the $k_{2} / k_{1}$ ratio from 0.65 to 0.35 . It is obvious that with the increase in temperature $\mathrm{AA}$ is consumed more quickly than MBA leading to the higher concentration of monoester in the reaction products. The same regularity was established for SA esterification by 3-

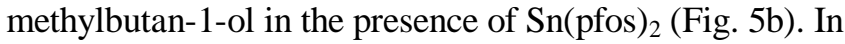
that case the $k_{2} / k_{1}$ ratio decreases from 0.33 to 0.16 within $360-420 \mathrm{~K}$.

In accordance with the data of kinetic investigations within $333-368 \mathrm{~K}[5,6]$ we calculated the values of $k_{2} / k_{1}$ ratio for $\mathrm{AA}$ and $\mathrm{SA}$ esterification by $\mathrm{C}_{2}-\mathrm{C}_{5}$ alcohols in the presence of TSA and $\mathrm{H}_{2} \mathrm{SO}_{4}$ (Fig. 6) within the temperature range of $360-420 \mathrm{~K}$. Such calculations are possible if activation energy insignificantly differs from the calculated one with temperature deviation by $30-50 \mathrm{~K}$.

In all cases (except AA esterification by ethanol in the presence of $\mathrm{H}_{2} \mathrm{SO}_{4}$ and $\mathrm{SA}$ esterification by ethanol in the presence of TSA and $\mathrm{H}_{2} \mathrm{SO}_{4}$ ) the increase in temperature decreases the $k_{2} / k_{1}$ ratio by higher or lesser degree. So, the increase in temperature accelerates DCA flow rate whereas the rate of $\mathrm{ME}$ conversion into $\mathrm{DE}$ increases slower. This leads to the increase in selectivity of the esterification intermediate product and its maximum yield. The higher yield of DCA monoesters and $\mathrm{C}_{3}-\mathrm{C}_{5}$ alcohols may be achieved while proceeding esterification under high pressure, because in such a case the boiling point of alcohol is higher.

For the consecutive reaction corresponding to the scheme $A \stackrel{k_{1}}{\longrightarrow} B \stackrel{k_{2}}{\longrightarrow} C$ the integral selectivity of the intermediate product $B(\mathrm{ME})$ for the reagent $A$ conversion $X_{A}$ is calculated according to Eq. (7):

$$
\Phi_{B}^{A}=\frac{1-X_{A}}{X_{A}} \frac{1}{k_{2} / k_{1}-1}\left[1-\left(1-X_{A}\right)^{k_{2} / k_{1}-1}\right]
$$

The yield of the product $B$ is calculated as a product of the reagent $A$ conversion and selectivity of the product $B$ formation:

$$
\eta_{B}^{A}=X_{A} \Phi_{B}^{A}=\frac{1-X_{A}}{k_{2} / k_{1}-1}\left[1-\left(1-X_{A}\right)^{k_{2} / k_{1}-1}\right]
$$

The selectivity of $B$ formation for the reaction with water distillation which takes place in the technological process under equimolar ratio of reagents or small excess of alcohol according to the scheme $A+Y \stackrel{k_{1}}{\longrightarrow} B+Y \stackrel{k_{2}}{\longrightarrow} C$, is calculated according to Eq. (7). Therefore this equation and obtained data of kinetic investigations may be used to calculate the maximum 
concentration and selectivity of monoalkylsuccinate and monoalkyladipinate formation in the reaction mixture.

The graphical dependencies (Fig. 7) plotted according to Eqs. (7) and (8) show that high values of ME selectivity and yield are achieved at very low $k_{2} / k_{1}$ ratio $(\sim 0.1)$. The increase in the $k_{2} / k_{1}$ ratio decreases the selectivity of ME formation and shifts its maximum toward lower value of DCA conversion. ME maximum yield is observed for $k_{2} / k_{1}$ ratio till 0.1 at high DCA conversion.

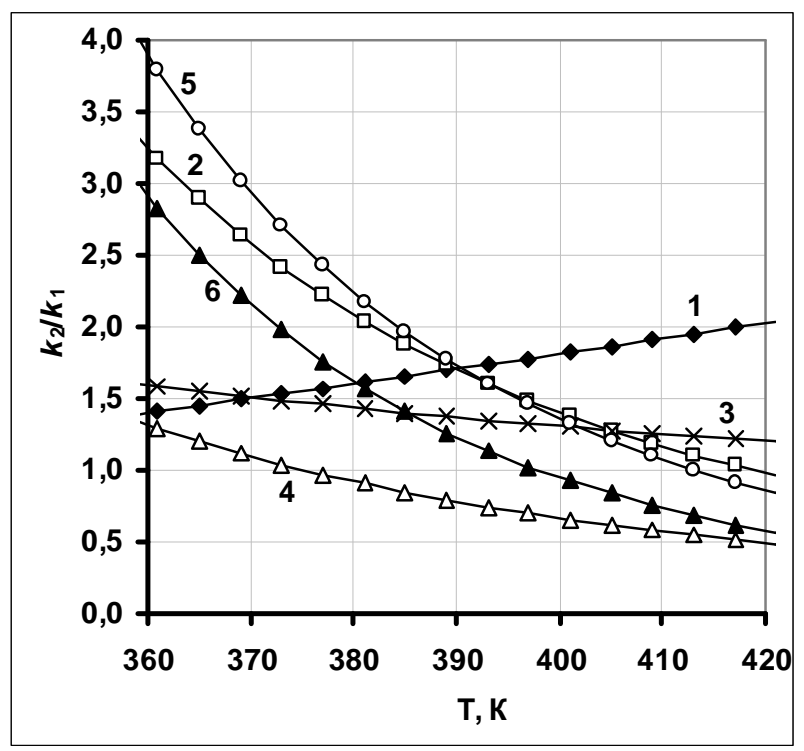

a)

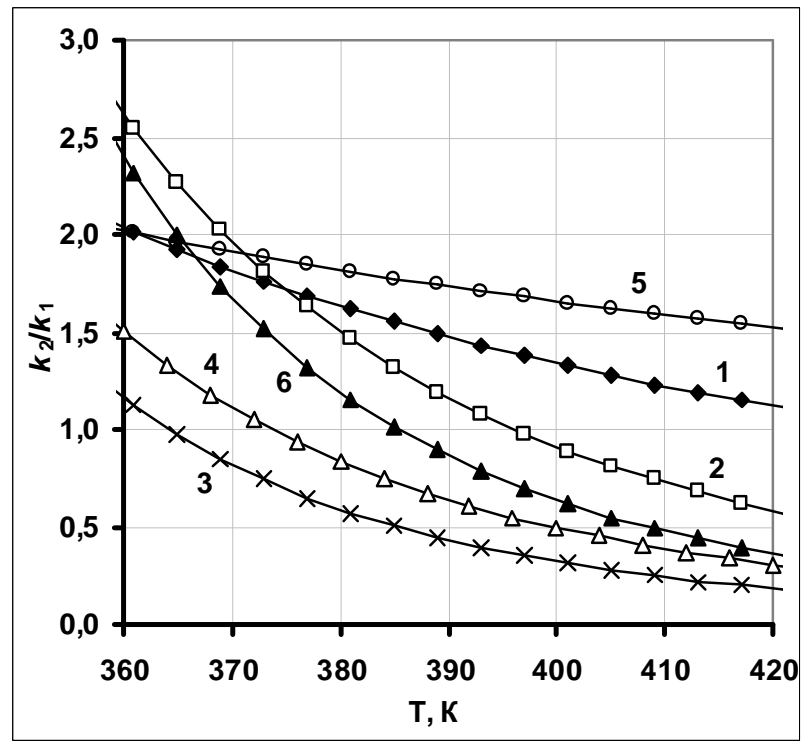

c)
The obtained conclusions are in good agreement with experimental results. For SA esterification by butan-

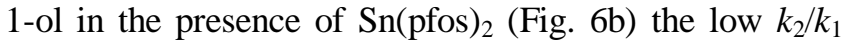
ratio (0.16-0.35) correlates with high yield of MiAC (70-74 \%) and low yield of DiAC at high SA conversion determined during the kinetic investigations (vide Fig. 2). Higher values of $k_{2} / k_{1}$ ratio $(0.35-0.65)$ for the reaction of AA esterification by butan-1-ol in the presence of TSA (Fig. 6a) provide lower ME yield ( 40\%).

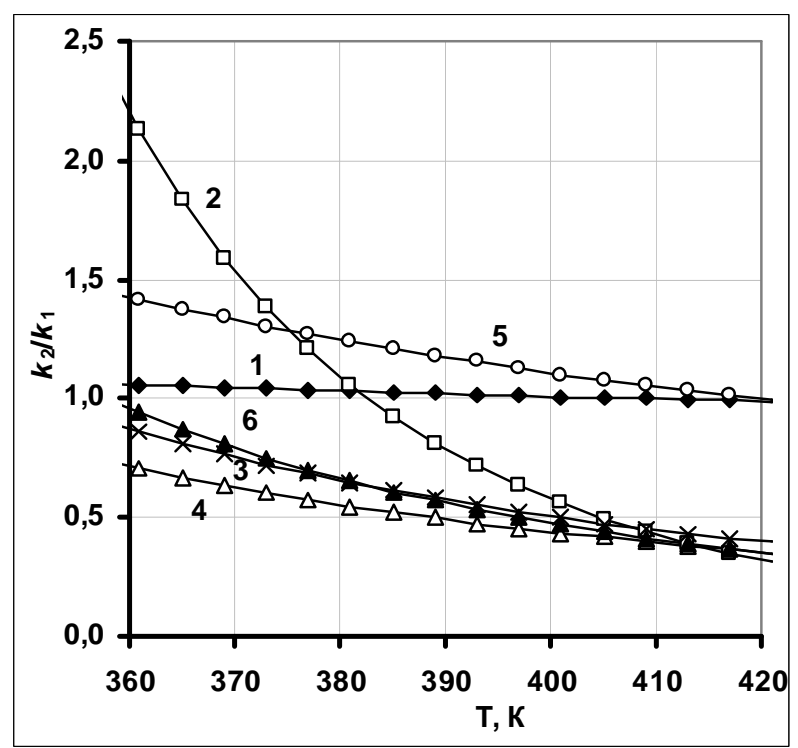

b)

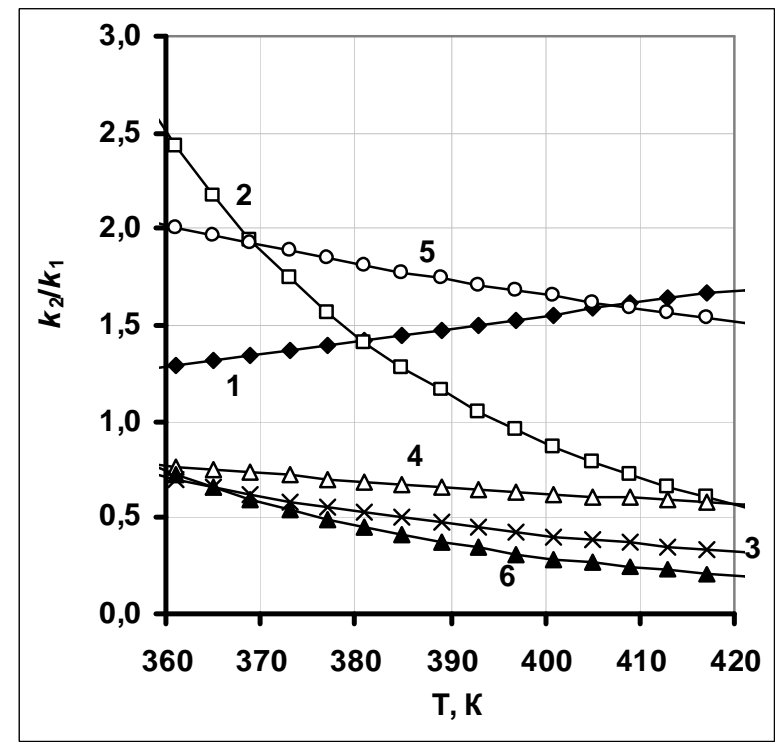

d)

Fig. 6. Temperature dependence of the calculated ratio $k_{2} / k_{1}$ for AA esterification in the presence of $\mathrm{H}_{2} \mathrm{SO}_{4}$ (a) and TSA (b); for SA esterification in the presence of $\mathrm{H}_{2} \mathrm{SO}_{4}$ (c) and TSA (d) by: ethanol (1); propan-1-ol (2); 2-methylpropan-1-ol (3); butan-1-ol (4); 3-methylbutan-1-ol (5) and pentan-1-ol (6) 


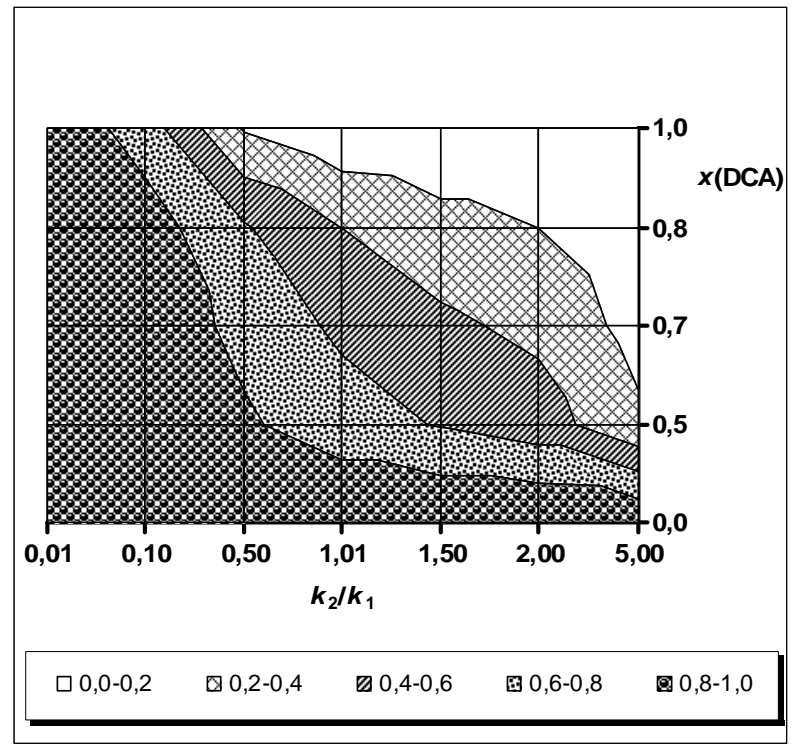

a)

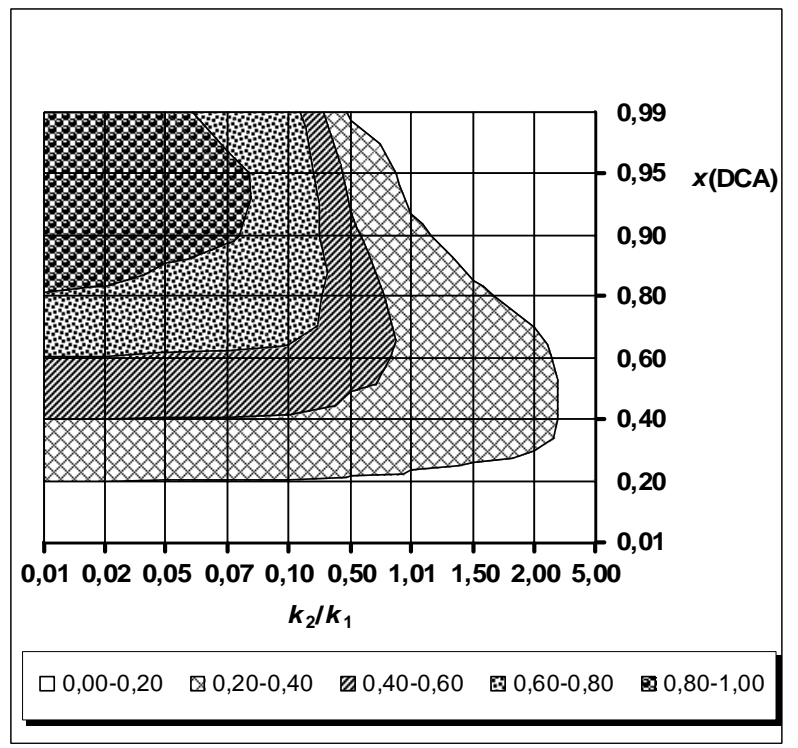

b)

Fig. 7. Dependence of selectivity of intermediate product formation (a) and its yield (b) on the rate constants ratio $k_{2} / k_{1}$ and DCA conversion

Thus, the maximum yields of AA and SA monoesters are achieved at the temperature ensuring the ratio $k_{2} / k_{1}<0.1$. However, for DCA esterification by $\mathrm{C}_{2}-\mathrm{C}_{5}$ aliphatic alcohols the high yields of monoesters (40-60\%) are possible only for some reaction systems, namely: SA-2-methylpropan-1-ol (catalysts $\mathrm{H}_{2} \mathrm{SO}_{4}$ and TSA) and SA-pentan-1-ol (TSA), for which $k_{2} / k_{1}$ ratio varies within $0.8-0.3(370-410 \mathrm{~K}) ; 0.6-0.35(370-410 \mathrm{~K})$ and $0.45-0.2(380-420 \mathrm{~K})$ (Figs. $6 \mathrm{c}$ and $6 \mathrm{~d}$ ).

It is evident from Eqs. (7) and (8) that selectivity of $\mathrm{ME}$ formation and its yield are independent of alcohol:DCA ratio. Therefore we recommend the equimolar ratio between these reagents to provide the maximum reaction rate.

\section{Conclusions}

Maximum selectivity of monoesters formation during their esterification by alcohols is achieved under the ratio between monoester and DCA flow rates less than 0.1 . The process temperature is one of the main parameters affecting the reaction rates, therefore the ratio between mono- and diesters may be controlled by its change during esterification. At the same time the reagents structure also affects the yield and selectivity of the reaction products. For AA and SA esterification by $\mathrm{C}_{2}-\mathrm{C}_{5}$ aliphatic alcohols the high yields of monoesters (40-60\%) are possible only for some reaction systems, namely: SA-2-methylpropan-1-ol (catalysts $\mathrm{H}_{2} \mathrm{SO}_{4}$ and TSA) and SA-pentan-1-ol (TSA). The obtained results may be used to select optimum conditions for DCA monoesters synthesis and achieving maximum yield of ME during obtaining mixed diesters via stepped addition of reagents-alcohols for esterification. They are also the basis for mathematical simulation of esterification in the industrial reactor and explanation of regulations of dicarboxylic acids esterification by alcohols mixture using by-products of different productions as the reagents.

\section{References}

[1] Freydlin G.: Alifaticheskie Dikarbonovye Kisloty. Khimiya, Moskwa 1978.

[2] Aptekman A. et al: Pat. RF 2280066. Publ. Jul. 20, 2006.

[3] Fizer L. and Fizer M.: Organicheskaya Khimija. Uglublennyi Kurs. Tom 2. Ripol Klassik, Moskwa 2013.

[4] Odabashyan G. and Shvets W.: Laboratornyi Practicum po Khimii i Technologii Osnovnogo Organicheskogo i Neftekhimicheskogo Sinteza. Khimiya, Moskwa 1992.

[5] Melnyk S.: Vostochno-Evrop. Zh. Peredovykh Techn., 2014, 67, 13.

[6] Melnyk S., Kachmar-Kos N., Melnyk Yu. and Reutskyy V.: IV Mezhdunar. Conf. "Suchasni Problemy Physichnoi Khimii", Ukraine, Donetsk 2009, 26.

[7] Pikh Z.: Theoriya Khimichnyh Protsesiv Organichnogo Syntezu. Vyd-vo Nats. Univ. "Lvivska politehnika”, Lviv 2002.

\section{СЕЛЕКТИВНІСТЬ УТВОРЕННЯ Й ВИХІД МОНО- ТА ДІЕСТЕРІВ ДИКАРБОНОВИХ КИСЛОТ ЗА СТАЦІОНАРНИХ УМОВ}

Анотація. Встановлено вилив температури, природи каталізатора, будови спирту й дикарбонової 
кислоти (ДК) та співвідношення реагентів на селективності утворення та вихід моно- та діестерів у реакиіях естерифікаиії адипінової (АК) та бурштинової (БК) кислот аліфатичними спиртами $C_{2}-C_{5}$ за стаціонарних умов. Теоретично $і$ експериментально доведено, що максимальна селективність утворення моноестерів ДК nід час їх естерифікаиї спиртами досягається при співвідношенні констант ивидкості витрати моно- естеру $i$ ДК, меншому ніж 0,1. Встановлено, щуо для естерифікації $A K$ і БК аліфатичними спиртами $C_{2}-C_{5}$ високий вихід (40-60\%) моноестеру можливий лише для таких реакиійних систем, як БК - 2-метилпропан-1-ол (каталізатори $\mathrm{H}_{2} \mathrm{SO}_{4}$ i пTCK) і БК - пентан-1-ол (nTCK).

Ключові слова: селективність, вихід, моноестер, дикарбонова кислота, спирти $C_{2}-C_{5}$. 